\title{
A CONSTRUÇÃO DA IDENTIDADE PÓS-MODERNA ATRAVÉS DA CAMPANHA: "O amor é a melhor herança. Cuide das crianças"
}

\author{
Post-modern identity construction through the campaign: \\ "Love is the best heritage. Care of children"
}

Ana Paula Albrecht Schifino ${ }^{1}$

\section{Resumo}

Este artigo pretende, juntamente com a fundamentação teórica que embasa este tema, apresentar a construção da identidade pós-moderna, através da campanha: "O Amor é a Melhor Herança. Cuide das Crianças". Tem a finalidade de explanar de que modo esta campanha se mostra como uma necessidade de compreensão e utilização dos meios de comunicação como ferramenta imprescindível dentro da atualidade, para se conhecer, esclarecer, questionar e duvidar os conhecimentos da realidade, pois a mídia não é só um veículo, mas também uma produtora de saberes e formas especializadas de se comunicar e também de produção de identidades dos sujeitos.

Palavras-chave: Identidade pós-moderna; Infância; Mídia.

\section{Abstract}

This article intends, together with the theoretical basis that support this issue, make the construction of the post modern identity through the campaign: "Love is the Best Heritage. Care of Children. " In order to explain the way in which this campaign is shown as a need for understanding and use the media considered an essential tool in the present time to know, clarify, question and doubt the knowledge of the reality, because the media is not only a vehicle, but also a producer of specialized knowledge and a way to communicate and also to produce identity of the subject.

Keywords: Post- modern identity; Childhood; Mass media.

\footnotetext{
Mestranda do PPGCOM da FAMECOS/PUCRS, Especialista em Administração e Organização de Eventos pela Pós-Graduação de Turismo e Eventos do SENAC-SP e Bacharel em Comunicação Social com habilitação em Relações Públicas pela FAMECOS/PUCRS. Curitiba PR. e-mail: apschifino@terra.com.br
} 


\section{Introdução}

De acordo com Kellner (2001), a cultura da mídia põe à disposição imagens e figuras com as quais seu público possa identificar-se, imitando-as. Desse modo, ela exerce importantes efeitos socializantes e culturais por meio de seus modelos de papéis, sexo e por meio de várias "posições de sujeito" que valorizam algumas formas de comportamento e modo de ser enquanto desvalorizam outros tipos de comportamento. Para este autor, a identidade pós-moderna é constituída teatralmente pela representação de papéis e pela construção de imagens, ela gira em torno do lazer e está focada na aparência e na imagem.

Segundo informações de relatórios obtidos no site da Rede Brasil Sul de Comunicação - RBS (2004), a empresa elegeu como sua principal bandeira institucional, no ano de 2003, uma campanha editorial e publicitária projetada para envolver gaúchos e catarinenses numa grande ação de proteção à criança e de luta contra a violência infantil. A empresa, acreditando que o tema tem pouca visibilidade na mídia e percebendo que as políticas públicas são insuficientes, lança a campanha: "O Amor é a Melhor Herança. Cuide das crianças", que utiliza personagens das histórias infantis (o lobo mau, a mula-sem-cabeça, o bicho-papão, a bruxa malvada, o diabo e o boi-da-cara-preta), que são temidos pelas crianças e os coloca em outro universo, como aliados na defesa da infância.

A simbologia de personagens populares das histórias infantis, antes tão assustadores e que agora se unem em defesa dos direitos das crianças, facilita a compreensão da mensagem transmitida, pois a imagem dos personagens monstros ultrapassa a dimensão da fantasia e atingi as relações diárias das famílias. Com essa campanha, a RBS se propõe a mobilizar a sociedade para a luta contra a violência infantil, veiculando mensagens que podem modificar as representações sociais de seus públicos sobre o sentido da infância, ou seja, oferecendo recursos para a construção de identidades pós-modernas.

Ainda segundo informações de relatórios obtidos no site da RBS (2004), a ampla repercussão da campanha junto à sociedade resulta no lançamento de sua segunda fase, no ano de 2004, que evolui para a busca de bons exemplos a serem multiplicados. Conforme Marcelo Rech (2004), diretor da Redação de Zero Hora, o desafio da cobertura jornalística da RBS não é fazer apenas a divulgação, pois a campanha tem uma missão transformadora, ou seja, a expressão maior da campanha é a perspectiva da mudança social e com ela a tentativa do estabelecimento de valores contrários à violência infantil. Em função disso, percebe-se a tentativa da RBS na elaboração de identidades por meio de modelos oferecidos por ela.

Assim, este artigo referente a conclusão da disciplina: Imagem e Pós-modernidade, orientada pela professora doutora Maria Beatriz Furtado Rahde, do Programa de Pós-Graduação da Faculdade de Comunicação Social da Pontifícia Universidade Católica do Rio Grande do Sul, pretende, juntamente com a fundamentação teórica que embasa este assunto, apresentar a construção da identidade pós-moderna por meio da campanha: "O Amor é a melhor Herança. Cuide das Crianças", com a finalidade de explanar o tema em estudo.

\section{A mídia na construção do imaginário infantil pós-moderno}

As novas tecnologias de mídia que atravessam a sociedade atual e todas as inovações advindas com elas promovem um reconhecimento e uma reflexão sobre a existência de um novo tipo de infância que a cultura midiática produz, muito diferente da então conhecida, tornada naturalizada. Uma nova infância, onde a construção do seu imaginário pode ser influenciada, entre outros fatores, por uma mídia que constantemente oferece fragmentos para a elaboração de identidades pós-modernas.

Para Maffessoli (2000), a televisão e a publicidade são tecnologias da interatividade que alimentam e são alimentadas por imaginários, ligando o emocional e a técnica. Existe lógica nisso, pois a lógica da imagem é sempre técnica. $\mathrm{Na}$ fonte, só existe imagem pela técnica. A imagem sempre importunou por ser uma criação humana, uma representação artificial criada pelo homem. A base da imagem é tecnológica. Quando existe exacerbação tecnológica, há abundância de imagens.

Ainda segundo o mesmo autor (2001), a influência dessas tecnologias na formação do imaginário social vem da idéia de manipulação que pertence ao esquema clássico, sustentado pelo marxismo, que considera o indivíduo indefeso diante da imagem. Isso vale para cinema, televisão, publicidade. Nesse modelo, o principal seria transmitir um conteúdo. Trata-se do primado da ideologia. 
A programação infantil é um espaço de projeções e identificações, em que os contos de fadas servem de ligação entre o mundo real e o mundo imaginário da infância. Desde os primórdios do cinema e principalmente na era da televisão, as mídias nos instigam a entender os "novos" estilos das emoções coletivas das crianças. Elas permanecem fascinadas durante longas horas diante da televisão. Ali, então, experimentam, simultaneamente, as sensações de prazer e de medo. Sob os diferentes aspectos da informação, pedagogia e divertimento, a mídia recorre às imagens que têm uma influência considerável junto às crianças.

Personagens criados pela mídia são passagens fundamentais na imaginação simbólica, entre outros motivos porque provocam uma reflexão dos mundos social e cósmico, incluindo as dimensões do consciente e inconsciente. Essas figuras formam imagens arquetípicas que persistem no imaginário coletivo como um meio de orientação, também na vida adulta. Podemos encontrar a epifanização destas figuras no contexto das imagens, sons e letras que constituem o campo das mídias, seja na literatura, no cinema ou na televisão. É considerável destacar que sob os estereótipos emanam significações ancestrais (arquetípicas) que podem esclarecer aspectos importantes do cotidiano.

O desenvolvimento infantil é um processo de adaptação que se produz na medida em que a criança consegue reconstruir a sua compreensão do mundo que a cerca. Segundo Durkheim (1975), os seres humanos possuem uma memória psicológica e as suas representações são a trama da vida social, que se originam das relações que se estabelecem entre os indivíduos assim combinados ou entre grupos secundários que se intercalam entre o indivíduo e a sociedade total. Seguindo esta visão, quando as crianças julgam valores sobre a vida real, elas buscam em sua memória as representações que até então tiveram acesso e as usam para distinguirem o certo do que é errado e conseqüentemente moldam as suas ações a partir destes valores.

As crianças, por estarem em fase de desenvolvimento, são singularmente mais suscetíveis à mídia e ao seu poder de persuasão, isto é, à sua capacidade em moldar atitudes. Suas influências são as mais diversas e significativas, pois ajudam a ditar regras culturais, transmitindo mensagens importantes e dignas de créditos sobre os comportamentos que exibe.
Os efeitos dos programas televisivos destinados a crianças não se restringem apenas aos hábitos da criança, existem ainda os efeitos colaterais, que se referem ao tipo de representação da realidade social que a criança aprende com toda programação exibida, tais como as novelas, os filmes, os desenhos, os programas de auditório, sem falar nas propagandas inseridas em quase todos os gêneros da programação infantil, dando margem a um consumismo desenfreado. Dentro desse contexto, ainda é importante ressaltar que a maior parte da programação televisiva distorce a representação do amor e do sexo, mostra a exacerbação da violência e induz ao conformismo.

Certamente, a televisão está repleta de modelos de papel adulto atraentes para as crianças e adolescentes. Na verdade, o modo mais efetivo para os pais ensinarem aos filhos certos comportamentos é demonstrar o comportamento e fazer com que as crianças modelem-se de acordo com este - precisamente o que a televisão faz. O que é observado pode ser imitado, ou pode simplesmente influenciar as crenças de uma criança sobre o mundo. (STRASBURGER, 1999, p. 20).

Para Bourdieu (1997), a mídia tem o poder de formar opiniões e atitudes em massa, tornandose perito ou guardiã de valores coletivos. Essa idéia reforça o fato de que os meios de comunicação são capazes de influenciarem uma sociedade por meio do conteúdo que transmitem. Portanto, no momento em que a mídia divulga ideais de cidadania, esta pode desenvolver valores em seus diversos públicos e reconstruir valores já existentes na memória destes, fato que pode gerar uma sociedade mais humana e cidadã.

Segundo Veet (2003), temas relativos ao desenvolvimento social, como miséria, pobreza, violência e desigualdades sociais, econômicas e culturais, entre outros tão presentes no cotidiano da nossa sociedade, são pauta constante dos meios de comunicação. Muitas vezes, porém, as questões ainda são abordadas a partir de uma visão reducionista dos problemas sem contexto social. Portanto, cabe à mídia ampliar o espectro do debate travado em nossa sociedade sobre esse universo. A missão desafiadora é contribuir de forma consistente com esforços pela redução desses problemas e para a promoção de um desenvolvimento que leve em conta não apenas estatísticas, mas, sobretudo, o bem-estar das pessoas. 
A mídia é um espaço público que pode permitir a participação de forma democrática de diversos grupos sociais e de interesses variados. Ela pode gerar sentidos, sejam eles positivos ou negativos. Quais ela estaria gerando em nossa sociedade?

Apesar dos limites, o espaço público midiático configura-se como o ambiente contemporâneo de maior potencial para a educação e a disseminação de informações para constituição de uma cultura global, voltada para a cidadania planetária. Trata-se da principal esfera pública de produção de sentidos da atualidade. Desta forma, é necessário refletir sobre o papel da comunicação na sociedade moderna, sua função social no uso do espaço público para construção e o exercício da cidadania e como instrumento de educação pública. (ROSA; MORIGI, 2004, p. 12).

A mídia se utiliza da persuasão para envolver seu público por meio de texto, imagem e som, as programações são criadas para resultar em altos índices de audiência e as estratégias para alcançar isso são fortes, apelativas e com grande poder na produção de sentidos que interferem na construção do imaginário infantil. Por tanto, na medida em que as crianças crescem e a representação do mecanismo midiático se aprofunda, pode-se tornar ferramenta importante na formação e na vivência das crianças como futuros adultos conscientes de valores sociais.

O público infantil não é uma entidade nula, ele se constrói historicamente e culturalmente através dos tempos. Devemos pensar sobre a infância aquilo que ela apresenta de tradição, de repetição, mas também de mudança. Referente à experiência humana, temos que nos voltar às tensões, aos conflitos e às mudanças que fazem parte na nossa vida. Evidentemente a velocidade de informação traz um elemento novo para a experiência humana em geral e o público infantil não está fora disso.

Vários autores que pesquisam a infância pós-moderna estão apontando para as mudanças nos comportamentos, na formação de valores, nos processos cognitivos e afetivos. Porém, não devemos nos deixar influenciar por visões negativas, pois cabe a todos, adultos e crianças, a responsabilidade de criar um futuro sempre melhor para a humanidade. Deste modo, se a mídia for utilizada para este fim, não temos por que temer.

\section{"O amor é a melhor berança. Cuide das criancas": na busca por uma identidade pós-moderna}

Segundo Kellner (2001), a cultura da mídia fornece imagens, discursos, narrativas e espetáculos capazes de produzir prazer, entidades e posições de sujeito de que as pessoas se apropriam. Para a sociedade de nossa época, ela fornece imagens daquilo que é apropriado em termos de modelos sociais, comportamentos sexuais, estilo e aparência. Desse modo, oferece recursos para a formação de identidades e mostra novas formas de identidade nas quais a aparência, o jeito de ser e a imagem substituem coisas como a ação e o compromisso na constituição da identidade, daquilo que alguém é.

Ainda segundo o mesmo autor (2001), houve um tempo que identidade era aquilo que se era, aquilo que se fazia, o tipo de gente que se era: constituía-se de compromissos, escolhas morais, políticas e existenciais. Atualmente, porém, ela é aquilo que se aparenta, a imagem, o estilo e o jeito como a pessoa se apresenta. E é a cultura da mídia que cada vez mais fornece material e recursos para a construção das identidades pós-modernas, para nos ditar a forma de agir e pensar.

A mídia pretende persuadir e, ao relatar a realidade da sociedade, apresenta aos receptores os assuntos sobre os quais é importante ter uma opinião e o que discutir. Alguns defendem que existe um número de fatores da realidade que os indivíduos não vivem diretamente nem definem inteiramente de acordo com sua vida, mas por mediação e intervenção simbólica da mídia. Além disso, os receptores não podem controlar a precisão exata da representação da realidade social, baseando-se em um modelo exterior aos meios de comunicação de massa. Conseqüentemente, elaboram uma imagem por meio desta representação que se torna distorcida, estereotipada ou manipulada.

No momento em que uma empresa de comunicação com o alcance da RBS assume um política de luta contra a violência infantil, adotando uma campanha de tom educativo, esta pode conseguir desenvolver valores em seus público. Dessa forma, fica evidente a importância da mídia na disseminação de valores positivos e o seu forte poder de influência sobre o público, em especial o infantil, por estar em fase de desenvolvimento. Pode ser capaz de gerar futuros adultos conscientes e avessos à violência infantil, influenciados, entre 
outros fatores, pelas representações de proteção à infância que o conteúdo da campanha expressa, ou seja, podendo gerar uma identidade pós-moderna, por meio de recursos fornecidos pela campanha.

As novas teorias da comunicação, por se voltarem ao receptor como o espaço onde os sentidos são negociados, introduzem uma nova forma de se interpretar os efeitos da mídia sobre os indivíduos. Pode-se concluir que o telespectador, ao receber diariamente informações sobre a campanha, reinterpreta-a conforme o seu cotidiano e os conhecimentos guardados em sua memória.

As representações sociais das crianças são construídas de acordo com os exemplos que elas têm de valores e crenças do meio ao qual elas se encontram inseridas e expostas. O universo infantil busca, em sua memória, a base para as suas representações sobre o que é certo ou errado e conseqüentemente moldam as suas ações a partir destes valores.

O significado da campanha passa por processo de negociação e o receptor desenvolve a oportunidade de se pautar de forma crítica. Assim sendo, as pessoas promovem discussões em torno das situações vividas pelos personagens da campanha, escolhendo os assuntos que mais se aproximam de sua própria realidade e dando a eles uma interpretação crítica pessoal.

Por tratar de temas próximos da realidade, essa campanha coloca em pauta assuntos sobre os quais deve existir um debate entre as pessoas. Certamente a divulgação desta campanha na mídia construiu um mecanismo comunicativo entre o seu público, isso porque ela se expandiu e circulou em vários meios de comunicação, fazendo despertar a consciência sobre a questão da violência e do comportamento em relação às crianças.

O fato de ser uma campanha bastante criativa, de fácil entendimento e memorização, foi provavelmente o que conquistou as crianças, ensinou a mensagem transmitida e assegurou a aceitação da campanha por todos. Certamente o tratamento dado ao tema e as representações desta campanha a fizeram circular e tocar o imaginário infantil.

A mídia veicula diversos tipos de representações sociais que conseqüentemente atingem os seus públicos, principalmente o infantil, pois este ainda se encontra em fase de construção de suas próprias representações. Esse fato certamente pode influenciar as atitudes das crianças sobre o mundo. Se os veículos de comunicação usarem esse poder de influência para formar e moldar atitudes de cidadania, estarão contribuindo para a construção de uma sociedade mais humana e solidária, para a formação de uma identidade pósmoderna cidadã.

\section{Conclusão}

Pode-se perceber que a mídia exerce grande influência em nossas vidas, quer seja como forma de lazer, quer seja pela atualização dos acontecimentos do mundo. O que não devemos negar é que a mídia exerce grande influência em nossas vidas, mais especificamente nas crianças, que não são passivas diante dela. A criança relaciona-se com as novas tecnologias da mesma maneira que se relaciona com o que está ao seu redor. Para ela, a programação da mídia constitui-se em um jogo simbólico, como são as brincadeiras infantis. A criança é receptiva das mensagens veiculadas pelos meios de comunicação, ela recria de acordo com suas experiências em um processo de troca de conhecimentos. Ela incorpora o que vê e ouve de maneira criativa, retirando o que lhe interessa naquele instante.

A mídia participa da construção de identidades na medida em que produz imagens, significações, enfim, saberes que de alguma maneira se dirigem à formação das pessoas, ensinando-lhes modos de ser e estar na sociedade em que se encontram, juntamente com outras referências que este sujeito adquire ao logo de sua vida, seja na escola, na família e na sociedade em geral. Os processos de subjetivação sempre são históricos e, portanto, cada época possui construções particulares do contexto no qual se está inserido. Somos consumidores das imagens e do conteúdo mostrado pela mídia diariamente e isso tem uma participação decisiva na formação das pessoas, mais especificamente na própria constituição do sujeito pós-moderno. Compreendendo que os meios de comunicação são parte integrante e fundamental de complexos processos de veiculação e de produção de significações, de sentidos, os quais estão interligados a modos de ser, de pensar, de conhecer e de se relacionar durante a vida.

A campanha "O Amor é a Melhor Herança. Cuide das Crianças" mostra-se como uma necessidade de compreensão e utilização dos meios de comunicação como ferramenta imprescindível 
dentro da atualidade para se conhecer, esclarecer, questionar e duvidar dos conhecimentos da realidade, pois a mídia não é só um veículo, mas também uma produtora de saberes e formas especializadas de se comunicar e também de produção de identidades dos sujeitos, assumindo, assim, uma função nitidamente pedagógica. Certamente, se utilizarmos a mídia como instrumento pedagógico, está poderá nos ajudar a ampliar e desenvolver consciência crítica sobre a sociedade em geral, os comportamentos, os valores, os sentimentos, os desejos e os prazeres, etc. $\mathrm{O}$ ato de olhar criticamente para a mídia possibilita ultrapassar as evidências e assim poder ir além do que nos é dado ver de imediato.

Esta campanha educativa buscou ser um meio de aprendizagem de valores contrários à violência infantil. As imagens e sons transmitidos por ela provavelmente acabaram por ter uma participação significativa na vida das pessoas, em especial das crianças, as quais se encontram em processo de formação de identidades. A campanha, por meio dos veículos de comunicação, invadiu lares e mostrou uma realidade que de alguma maneira pautou, interpelou e orientou o cotidiano de milhões de pessoas. Essas informações veiculadas durante a campanha participaram certamente da produção da identidade individual e social de muitos sujeitos e operaram sobre a construção de seu imaginário.

\section{Referências}

BOURDIEU, Pierre. Sobre a televisão: seguido de a influência do jornalismo e os jogos olímpicos. Rio de Janeiro: Jorge Zahar, 1997.

DURKHEIM, Émile. Representações coletivas e representações individuais. In: Filosofia e sociologia. 2. ed. Rio de Janeiro: Forense Universitária, 1975. p. 15-49.

KELLNER, Douglas. A cultura da mídia. São Paulo: EDUSC, 2001.
MAFFESOLI, Michel. O tempo das tribos: o declínio do individualismo nas sociedades de massa. 3. ed. Rio de Janeiro: Forense, 2000.

RBS. Histórico da campanha. 2004. Disponível em: <www.clicrbs.com.br/cuidedascriancas>. Acesso em: 07 maio 2004.

RECH, Marcelo. Os monstrinhos estão de volta. Zero Hora, Porto Alegre, 11 de maio de 2004. Geral, p. 4-5.

ROSA, Rosane; MORIGI, Valdir. Cidadania midiatizada, cidadão planetário. Comunicação e Espaço Público, ano 7, n. 1-2, p. 81-93, 2004.

SILVA, Juremir Machado da. O imaginário é uma realidade. Revista Famecos, Porto Alegre, n. 15, p. 74-81, ago. 2001.

STRASBURGER, Victor C. Os adolescentes e a mídia: impacto psicológico. Porto Alegre: Artes Médicas Sul, 1999.

VEET, Vivarta. Que país é este? pobreza, desigualdade e desenvolvimento humano e social no foco da imprensa brasileira. São Paulo: Cortez, 2003.

Recebido em: 08/03/2007 Received in: 03/08/2007 Aceito em: 14/04/2007 Accepted in: 04/14/2007 